\title{
SMALL SYNAPTIC POTENTIALS IN BURST ACTIVITY OF LARGE NEURONS IN THE LOBSTER CARDIAC GANGLION
}

\author{
Kenro TAZAKI \\ Biological Laboratory, Nara University of Education, Nara 630, Japan
}

Summary Some characteristics of synaptic potentials arising in the large cells of the lobster cardiac ganglion were investigated by means of intracellular recording and current injection.

1. The spontaneous burst was mainly composed of two kinds of synaptic potentials differing in various features, indicating that the large cells were innervated by two common presynaptic nerve fibers from pacemakers.

2. Antifacilitation was observed in large synaptic potentials, while it was not observed in small synaptic potentials.

3. Depolarization of the large cell accelerated the initiation of large synaptic potentials, and hyperpolarization impeded it. The electrotonic interaction between large cells and the presynaptic nerve cells, which produce large synaptic potentials, was rather strong.

4. Polarization of the large cell had less effect on the initiation of small synaptic potentials than on that of large synaptic potentials; the electrotonic interaction between large cells and the presynaptic nerve cells, which produce small synaptic potentials, was exceedingly weak.

5. A brief current pulse applied to the large cell evoked the slow potential, which was separated from a train of small synaptic potentials. The positive feedback of the slow potential was demonstrated well.

6. Repetitive small synaptic potentials had an acceleratory effect on the burst initiation. The rate of slow depolarization increased with development of small synaptic potentials.

7. Two types of presynaptic nerve cells exhibited differences in time courses of repetitive discharges; one produced a brief train of discharges, and the other an extensive train.

8. It was concluded that the large cells are controlled by two types of presynaptic nerve cells; one evokes large synaptic potentials, initiating impulses, and the other induces small synaptic potentials, increasing excitability of the postsynaptic membrane. The latter controls the

Received for publication July 21, 1971

田崎健郎 
former. The large cell behaves as a pacemaker when presynaptic nerve cells become inactive or when their activities are delayed.

The cardiac ganglion of the lobster contains nine nerve cells and exhibits spontaneous periodic burst discharges (WELSH and MAYNARD, 1951). Intracellular potentials in the large cell are composed mainly of synaptic potentials and spikes, their characteristics having been reviewed by HAGIWARA (1961). Synaptic potentials are produced by presynaptic impulses from pacemaker cells, which are found among small cells located in the posterior part of the ganglionic trunk (MAYNARD, 1955; HAGIWARA and BULLOCK, 1957). Large cells are followers and exhibit a marked synchronization among individual synaptic potentials during the burst discharge, indicating that they are innervated by common presynaptic nerve fibers (HAGIWARA et al., 1959). The electrical interaction among large cells plays an important role in synchronization (WATANABE, 1958); interaction occurs between followers and pacemakers, the activity of the former accelerating that of the latter (WATANABE and BULLOCK, 1960); pacemaker-pacemaker interaction is presumed but has not been clearly demonstrated (MAYNARD, 1955).

Synaptic potentials of widely varying shapes and sizes are found during the burst of the large cell. This variety has generally been understood as the effect of antifacilitation (HAGIwARA and Bullock, 1957; Bullock and Horridge, 1965). Nevertheless, there are some variations in synaptic potentials that are not explained by antifacilitation (BULlock and Terzuolo, 1957); it is observed that small synaptic potentials follow or precede the large synaptic potentials. No detailed investigation of the small synaptic potentials has, however, been made.

The present paper is concerned with two kinds of synaptic potentials that appear in the large cell of the lobster cardiac ganglion. Furthermore, the interaction between presynaptic nerve cells, pacemakers, is demonstrated.

\section{METHODS}

The cardiac ganglion of the Japanese spiny lobster, Panulirus japonicus, was used in this study. The anatomy and the method of dissection of the lobster heart have been described by MATSUI (1955). The ganglionic trunk was laid bare by removing the surrounding muscle and was mounted in a small lucite chamber with the remaining heart muscle firmly pinned. AlEXANDrowicz (1932) observed five large cell somata in the anterior part of the trunk and four small ones in the posterior part. MAYNARD (1955) designates these large cells Cell 1, Cell 2, etc., from the rostral side.

The bathing solution chosen for use in this study was natural sea water, because it is the best way to keep the regular rhythm of the spontaneous burst of the ganglion (WATANABE and Bullock, 1960). 
Glass pipette microelectrodes filled with $3 \mathrm{M} \mathrm{KCl}$ were employed for internal recording and stimulation. Their electric resistances ranged from 20 to $30 \mathrm{M} \Omega$. Intracellular potential changes from large cell somata were recorded by means of an input cathode follower with low grid current and a DC amplifier and were displayed on a dual beam cathode-ray oscilloscope. In most experiments, simultaneous recordings were made from two somata of Cells 1-4. For polarizing the cell membrane, another electrode was introduced into one of the two somata. A polarizing current pulse with relatively long duration was supplied from an electronic stimulator through a resistance of $5 \times 10^{7} \Omega$. As described by WATANABE and BULLOCK (1960), this current pulse was more effective for initiation or inhibition of the burst than a brief pulse. In some experiments a brief pulse $5 \mathrm{msec}$ in duration was used to stimulate the large cell directly.

All experiments were carried out at room temperatures ranging from 20 to $25^{\circ} \mathrm{C}$.

\section{RESULTS}

\section{Spontaneous burst}

The large cell exhibits a complex pattern of electrical activity. A typical example is shown in Fig. 1A. The burst was initiated by a large synaptic potential followed by successive potentials graded in amplitude and frequency. These large synaptic potentials are capable of initiating spikes. A train of small synaptic potentials followed successive large synaptic potentials. These small synaptic potentials rarely initiated spikes. In some cases they appeared following large synaptic potentials, and in other cases preceding them. In the present paper the electrophysiological characteristics of the small synaptic potential will be described and compared with those of the large synaptic potential.

Trains of both large and small synaptic potentials were synchronously produced in large cells, being repeated at regular intervals. Such synchronization was observed in any combination of four large cells, Cells 1-4 (Figs. 1 and 2). As suggested by Bullock and Terzuolo (1957), it is unlikely that both synaptic potentials are induced by the activity of a single presynaptic nerve fiber, and that the size differences resulted from antifacilitation. Instead, they probably originate from different presynaptic neurons among the pacemaker cells. We assume that large cells receive inputs from at least two kinds of presynaptic neurons. Evidence for this assumption will be given later. In the present paper the presynaptic neurons that induce the small synaptic potential will be called Type A neurons, and the presynaptic neurons that induce the large synaptic potential will be called Type B. Although the impulse activities of these cells could not be recorded, their properties were inferred from the results of the large and small synaptic potentials. 

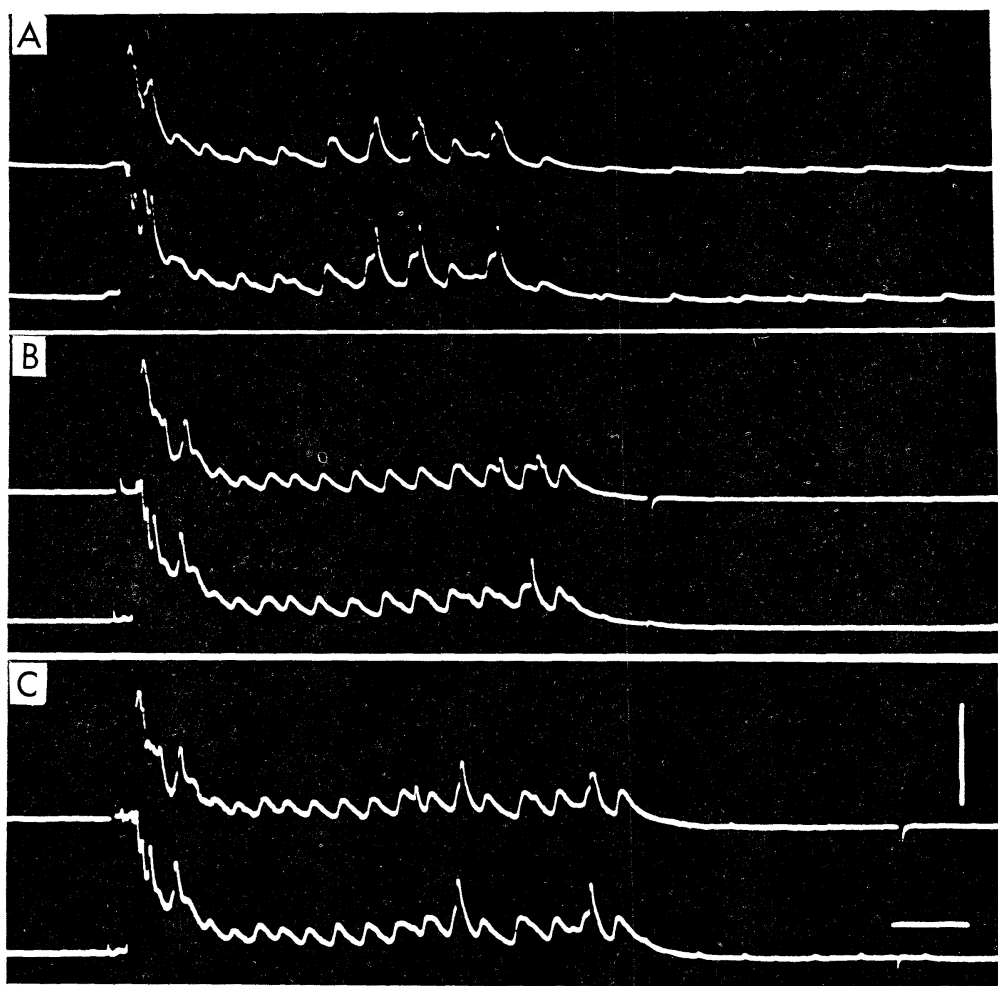

Fig. 1. Large and small synaptic potentials in large cells. Upper: Cell 1; lower: Cell 4. A: spontaneous bursts. Successive large synaptic potentials were followed by a train of small synaptic potentials. B and C: large synaptic potentials elicited by application of depolarizing current to Cell 5 . The duration of the applied current is marked by a slight artefact. Calibration: $20 \mathrm{mV}, 100 \mathrm{msec}$.

\section{Large synaptic potentials}

The general character of large synaptic potentials has been investigated in detail by Hagiwara and Bullock (1957) and Hagiwara et al. (1959).

a) Initiation of large synaptic potential The burst was evoked by applying a long depolarizing current pulse to a large cell. Figures $1 \mathrm{~B}$ and $1 \mathrm{C}$ show the responses. When a depolarizing current pulse was applied to a large cell (Cell 5), bursts similar to the natural ones were elicited. In this case the stimulus was given during the interburst period with sufficient interval between it and the preceding burst. Large synaptic potentials were successively produced during stimulation, while no small synaptic potentials were found in the elicited burst. The number of large synaptic potentials increased with an increase in current intensity. However, the train of large synaptic potentials terminated before termination of the current pulse when duration of the current pulse was prolonged (Fig. 1C). 

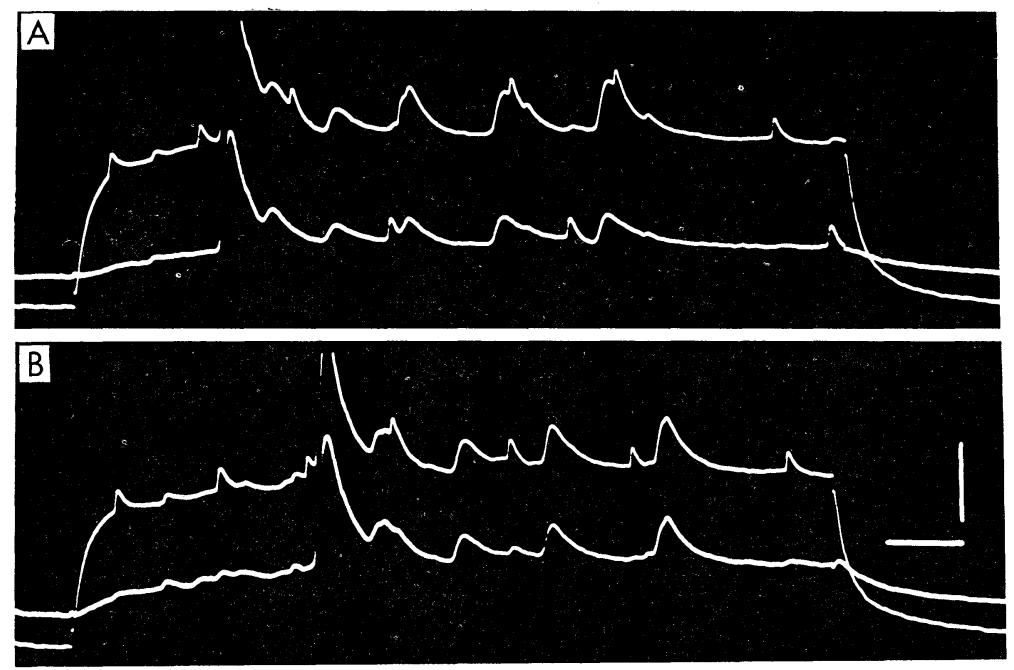

Fig. 2. Changes in the response interval of large synaptic potentials during depolarization. Upper: Cell 4 in A and Cell 3 in B; lower: Cell 2. Outward current was applied to Cell 2. Small brief depolarized deflections are spikes. Calibration: $10 \mathrm{mV}, 50 \mathrm{msec}$.

Intervals between large synaptic potentials increased gradually during a burst discharge. Similar results were obtained when a large cell other than Cell 5 was stimulated. An example is presented in Fig. 2. Potential changes were simultaneously recorded from Cells 2 and 4 in A, and from Cells 2 and 3 in B, in the same preparation, and currents were applied to Cell 2. Large cells responded repeatedly with synchronous large synaptic potentials on depolarization, but they stopped responding while the membrane was still being depolarized. Progressive increase of the response interval was observed during repeated responses.

The initial large synaptic potential was remarkably large in amplitude, compared to the following ones, as shown in Figs. 1 and 2. Furthermore, their amplitude changed markedly during the response, increasing toward the later part of the burst with increasing intervals, indicating a relationship with frequency. This result is in good accordance with those reported by HAGIWARA and BULLOCK (1957), and such a phenomenon has been called antifacilitation by BuLlock and HorRIDGE (1965).

Depolarization of the large cell had noticeable effects on the rhythm of the Type B presynaptic neurons. WATANABE and Bullock (1960) have reported that electrotonic interaction occurs between follower and pacemaker cells. Their pacemaker cells are probably equivalent to Type B neurons in this study, because the synaptic potential observed by the researchers was larger in amplitude. It can be presumed that depolarization of the large cell has some effect on the activity of Type B neurons, eliciting a train of presynaptic impulses. Therefore, the gradual increase of the response interval and the termination of the response 
during stimulation, such as are shown in Figs. 1 and 2, are attributed to the nature of Type B neurons. It is probable that Type B neurons produce only a brief train of discharges. The large cells and Type B neurons are interconnected by electrotonic pathways which provide the electrotonic coupling.

\section{Small synaptic potentials}

The small synaptic potential was about $1 \mathrm{mV}$ in amplitude. It reached its peak within $10 \mathrm{msec}$ and decayed with an exponential time course. The small synaptic potential appeared repeatedly during a burst, with a fairly regular interval. The number in a burst ranged from 10 to 20 ; the frequency varied greatly from preparation to preparation, ranging from 70 to 200 per minute. In some cases the train of small synaptic potentials continued for long periods (up to $5 \mathrm{sec}$ ). The amplitude did not change during the train. In contrast with the large synaptic potential, neither facilitation nor antifacilitation was found.

Through current injection into a large cell, separation of large and small synaptic potentials was successfully performed. Injection of depolarizing current into a large cell during the interburst period elicited large synaptic potentials, but it did not elicit small synaptic potentials. The current intensities were between $10^{-9}$ and $10^{-8} \mathrm{~A}$.

a) Effect of hyperpolarization. A hyperpolarizing current pulse of a long duration (approx. $4 \mathrm{sec}$ ) inhibited the initiation of large synaptic potentials. An example is shown in Fig. 3. The current intensity was about $7 \times 10^{-9} \mathrm{~A}$. Trains of both large and small synaptic potentials were periodically initiated (Fig. 3A). When inward current was applied, large synaptic potentials were completely eliminated during hyperpolarization (Fig. 3C). However, small synaptic potentials remained; they were repeated at regular intervals. After the end of current injection, repolarization to the resting potential level produced large synaptic potentials (Fig. 3D); thereafter, a greater number of large synaptic potentials appeared during development of small synaptic potentials (Fig. 3E).

The above-mentioned findings confirm the hypothesis that the large and small synaptic potentials are independent activities originating from separate synapses in a large cell, and indicate that two kinds of presynaptic nerve cells exist among small cells and that their fibers establish synapses with all the large cells. Hyperpolarization of a large cell impeded the activity of Type B neurons only, but not the activity of Type A neurons. The results shown in Figs. 1 and 3 indicate that Type B neurons are much more easily affected by polarization of a large cell than are Type A neurons, which are affected only by a polarizing current with an intensity of a different order of magnitude (see Section $c$ ).

Hyperpolarization caused an increase in amplitude of the small synaptic potential. An example is shown in Fig. 4. When inward currents with varying intensities were applied during the occurrence of small synaptic potentials, their amplitude increased progressively with increasing membrane potential. Variation of 


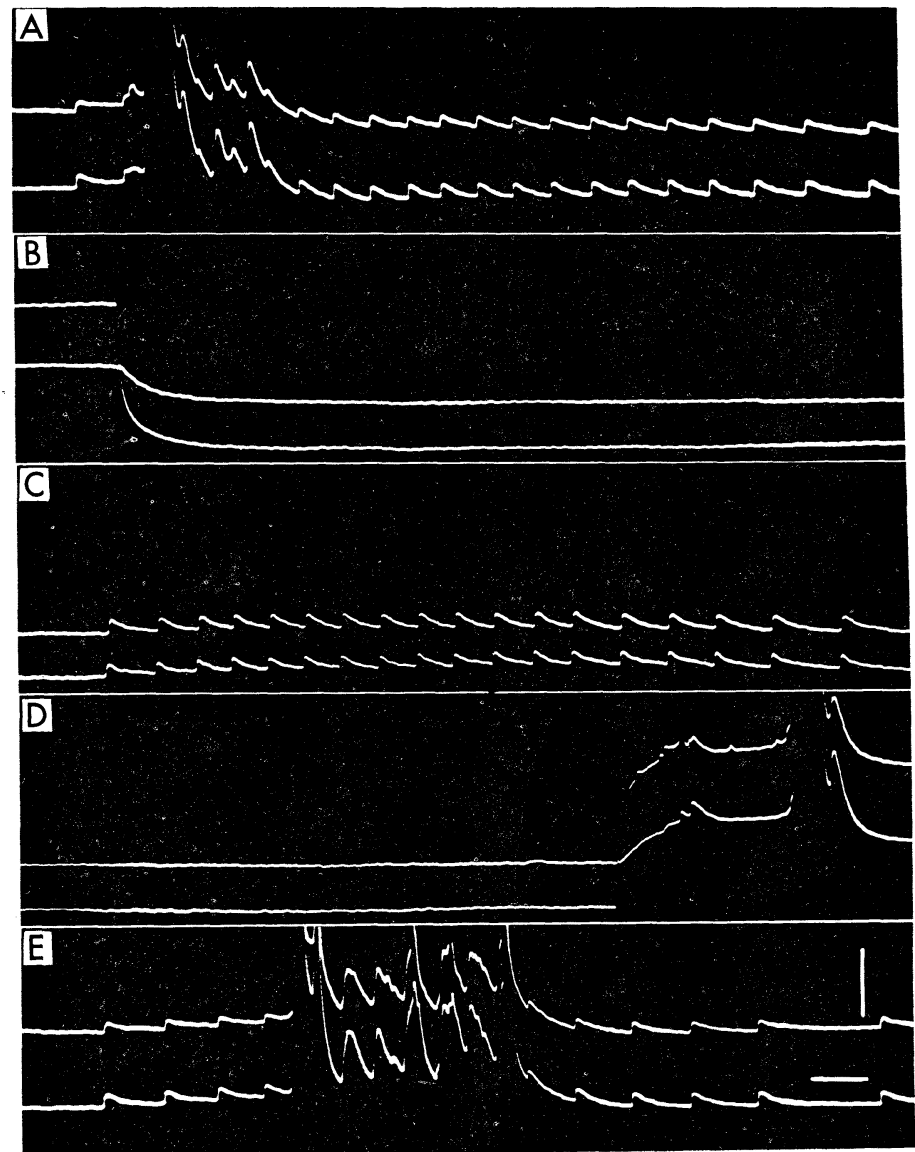

Fig. 3. Effects of hyperpolarization on burst initiation. Upper: Cell 4; lower: Cell 1. A-E are from a continuous recording. A: spontaneous bursts. B: onset of current application. C: large synaptic potentials were eliminated. D: after current application. $\mathrm{E}$ : spontaneous bursts. The train of small synaptic potentials repeated regularly. Calibration: $5 \mathrm{mV}, 100 \mathrm{msec}$.

the membrane potential showed a linear relationship to the size of the small synaptic potential, though displacement of the membrane potential was made only on hyperpolarization. The extrapolated reversal potential was about $0 \mathrm{mV}$. Such a relationship has been observed between the large synaptic potential and its measured reversal potential (HAGIWARA et al., 1959).

b) Effect of a brief current pulse. In some cases a train of small synaptic potentials preceded the burst. An example is shown in Fig. 5. Successive small synaptic potentials slightly shifted the membrane potentials of both cells, initiating the bursts (Fig. 5A). The interval between trains of small synaptic potentials was about 2 sec. Two large cells exhibited different froms of activities; one produc- 


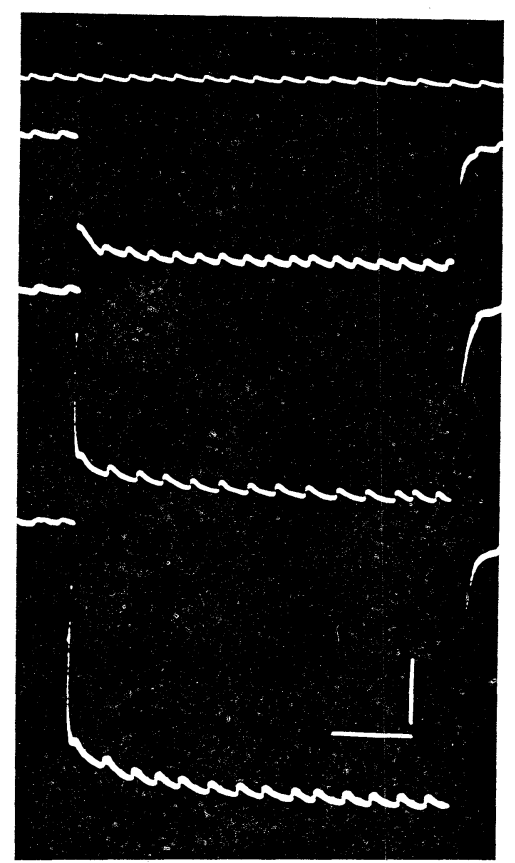

Fig. 4. Effect of hyperpolarization on the amplitude of the small synaptic potential. Inward currents of various intensities were applied during the development of small synaptic potentials. Top trace, at the resting potential, which was about $45 \mathrm{mV}$. Calibration: $10 \mathrm{mV}, 100 \mathrm{msec}$.

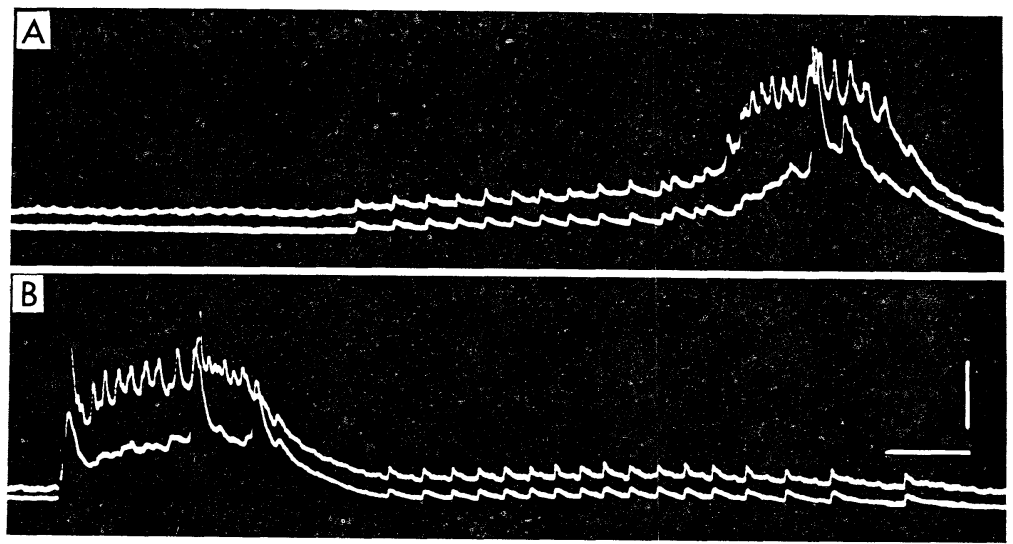

Fig. 5. Effect of a brief current pulse on burst initiation. Upper: Cell 3; lower: Cell 2. A: spontaneous bursts. The train of small synaptic potentials repeated with an interval of $2 \mathrm{sec}$. B: a brief pulse of $5 \mathrm{msec}$ was applied to Cell 3 before the appearance of small synaptic potentials. Calibration: $10 \mathrm{mV}, 100 \mathrm{msec}$. 
ed a slow potential with superimposed spikes, and the other developed large synaptic potentials. Separation of such activities and small synaptic potentials was done by stimulating large cells, as shown in Fig. 5B. On application of a brief outward current pulse (approx. $5 \mathrm{msec}$ ) a slow potential and large synaptic potentials were elicited, respectively, in the two cells, preceding small synaptic potentials. The stimulus was given $1.6 \mathrm{sec}$ after the preceding initial small synaptic potential. The interval of the train of small synaptic potentials was not affected by the stimulus. The result of Fig. 5 indicates that the large cell is activated by development of small synaptic potentials and that it generates the slow potential.

It has been reported that the slow potential is spontaneously produced in the large cell (WATANABE, 1958), and that a slow potential change affects the activity of the pacemaker cell, while a rapid potential change such as a brief pulse does not (WATANABE and Bullock, 1960). From these facts it is inferred that the brief pulse elicits the slow potential, which affects the firing of Type B presynaptic neurons similarly to depolarization produced by current injection, and large synaptic potentials are evoked in the large cell thereby. Thus, the positive feedback of the slow potential change (WATANABE and BULLOCK, 1960) is well illustrated in this example.

c) Initiation of small synaptic potentials. Larger depolarization induced successive small synaptic potentials in the large cell. Figure 6 shows an example of the response. The records were obtained from Cells 2 and 5. Cell 2 produced the slow potential with superimposed spikes, exhibiting neither of the two synaptic potentials, and Cell 5 was inactive (Fig. 6A). These facts indicate that the large cell is capable of initiating the burst of spikes without any presynaptic inputs. Thus, it behaves as a pacemaker because activity of the presynaptic nerve cells stops under some experimental conditions. When an outward current with a higher intensity, on the order of $10^{-7} \mathrm{~A}$, was applied to Cell 5, Cell 2 responded with a train of small synaptic potentials (Figs. 6B, C and D), presumably because of activation of the presynaptic nerve cells. The small synaptic potentials occurred repeatedly during current injection, and their frequency increased with rising current intensity. When the current electrode was withdrawn from Cell 5, a stimulus with the same current intensity had no effect on the initiation of the small synaptic potentials. These facts indicate the existence of electrotonic pathways between large cells and Type A presynaptic nerve cells, though electrotonic coupling is extremely weak. Termination of the response during stimulation, as seen in Type B neurons did not occur here. Type A neurons sometimes produce rather extensive repetitive discharges of presynaptic impulses, inducing successive small synaptic potentials. A longer series of small synaptic potentials elicited slow potentials twice (Figs. 6C and 6D), indicating that they increased the activity of the large cell.

d) Acceleratory effect. Small synaptic potentials had an acceleratory effect on the burst activity. When the burst was preceded by a slow depolarization arising continuously during the interburst period, acceleration due to small synaptic 


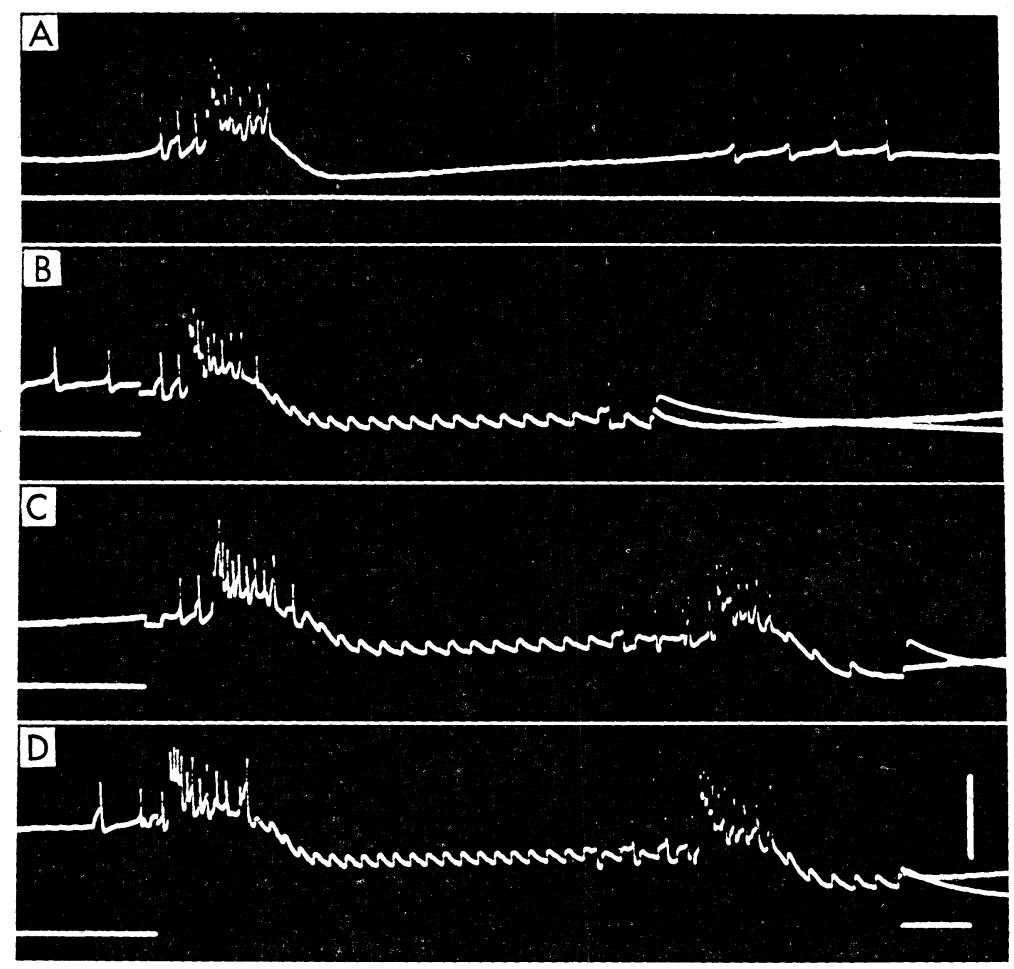

Fig. 6. Initiation of small synaptic potentials. Upper: Cell 2; lower: Cell 5. A: spontaneous activities. Cell 2 produced a burst of spikes superimposed on the slow potential. Cell 5 was inactive. B, C, and D: outward currents were applied to Cell 5. B and C: at the same current intensities. D: at stronger intensity. Depolarized potential changes of Cell 5 scaled out. Calibration: $10 \mathrm{mV}, 100 \mathrm{msec}$.

potentials was observed. An example is shown in Fig. 7, where potentials were simultaneously recorded from Cells 1 and 5. The frequency of the burst depended on the rate of slow depolarization in the same way as that of the action potential in the vertebrate heart (WEIDMANN, 1956). In Fig. 7A the rate was about $4 \mathrm{mV}$ / sec. The development of small synaptic potentials in both cells increased the rate, causing the initiation of burst earlier (Fig. 7B); the rate increased to $6 \mathrm{mV} / \mathrm{sec}$. The increase of activity such as is shown in Figs. 6C and 6D is thought to be due to the acceleratory effect of small synaptic potentials. The acceleration occurred only during activation of small synaptic potentials. In some cases, on repetitive small synaptic potentials, two brief trains of large synaptic potentials occurred in succession, indicating that Type B presynaptic nerve cells are activated by development of small synaptic potentials. The membranes of large cells exhibited slight depolarization during the development of small synaptic potentials.

The frequency of small synaptic potentials increased progressively with time 


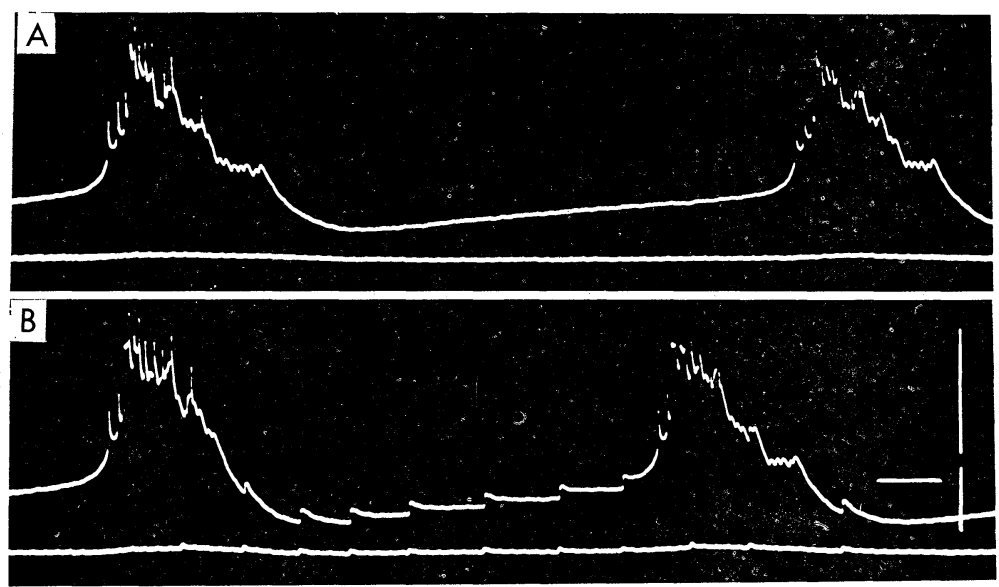

Fig. 7. Acceleratory effect of small synaptic potentials on the slow depolarization. Upper: Cell 1; lower: Cell 5. A: control. B: effect of small synaptic potentials arising in both cells. Calibration: $10 \mathrm{mV}, 100 \mathrm{msec}$.

and reached a steady level which was followed by a progressive decrease (Figs. 3C, $5 \mathrm{~B}$ and 7B). It is inferred that repetitive discharges of presynaptic impulses in Type A neurons have a similar time course. The time course of repetitive responses of small synaptic potentials differed greatly from that of the large synaptic potentials, as shown in Figs. 1 and 2. This difference is due to the differences in repetitive discharges of the two kinds of presynaptic nerve cells; one is thought to produce a brief train of discharges, and the other a long-lasting train of discharges.

\section{DISCUSSION}

In the lobster cardiac ganglion the large cells produced large and small synaptic potentials during spontaneous burst discharges. Separation of these two electrical events was achieved by current injections into large cells.

The electrophysiological characteristics of a synaptic potential have been described by HagiwARA and BULlock (1957) and HagiwARA et al. (1959). The synaptic potential investigated by them is regarded as equivalent to the large synaptic potential described in this paper, in view of its shape and size. In the present experiments, with respect to the large synaptic potential, similar results were obtained; antifacilitation occurred during repetitive responses; the response interval increased gradually; and its initiation was affected by polarization of the large cell.

The characteristics of small synaptic potentials is quite different from those of large synaptic potentials in various respects: it has been observed that the small synaptic potentials outlast the large synaptic potentials (Bullock and TERzUOLO, 
1957); the size of the former is much smaller; they do not initiate spikes; and antifacilitation does not occur. The activity of the Type A presynaptic nerve cells is not influenced as much by the potential changes of large cells as that of Type B nerve cells.

Activity of the two types of presynaptic nerve cells showed differences in both the time courses of repetitive discharges and the effects on the large cell membrane. In crustacean muscles there are two kinds of motor fibers which induce distinctive junction potentials in the same muscle fiber; one evokes a large junction potential, and the other a small one (Hoyle and Wiersma, 1958; WiERsMA and BoBberT, 1961). Further, the former tends to produce a brief train of discharges, while the latter a long-lasting train of discharges (WRIGHT and ADELMAN, 1954). In the impulse activities of the lobster cardiac ganglion, similar differences have been observed between large and small cells (MAYNARD, 1955). In the present study it was found that the two types of presynaptic nerve cells exhibit activities that closely resemble those of the motor fibers of doubly innervated crustacean muscles.

Extensive repetitive activation of small synaptic potentials accelerated the burst initiation (Figs. 3, 6, and 7). MAYNARD (1955) found that small impulses arising in the small cells increased the activity of the large cell. This fact is thought to be similar to the results of the present study. In the lobster cardiac ganglion such acceleration is also observed when the extrinsic acceleratory nerve from the central nervous system is stimulated (MAYNARD, 1953; TerzuOlo and Bullock, 1958; OtANi and Bullock, 1959; Shimahara, 1969a). However, a unitary excitatory postsynaptic potential corresponding to the stimulus to the nerve is not found, while an inhibitory one has been observed (SHImAHARA, 1969a, b). Similar observations have been reported in the Squilla cardiac ganglion (WATANABE et al., 1968, 1969). The acceleratory process in the course of repetitive small synaptic potentials differs greatly from that resulting from stimulation of the extrinsic nerve: a unitary synaptic potential appeared; no prominent depolarization developed; and acceleration was limited during synaptic activation. The rate of slow depolarization increased during development of small synaptic potentials (Fig. 7). This is similar to the results of stimulation of the extrinsic nerve (SHIMAHARA, 1969a). Comparable observations have been made regarding the acceleratory effect on the slow depolarization during the stimulation of the sympathetic nerve in the vertebrate heart (HUTTER and TRAUTWEIN, 1956).

The electrotonic interaction between large cells and Type A neurons is extremely weak; the electrical activity of the latter cell may not be affected normally by the potential changes of the large cells. The fibers of Type A neurons innervate, respectively, five large cells, controlling their activities. Also, Type A neurons seem to establish a synapse with Type B presynaptic cells, because the initiation of a large synaptic potential was activated by development of repetitive small synaptic potentials (Figs. 3 and 5), while no reverse action was found. It can be presumed 
that the Type A neurons control Type B neurons, increasing the activity of the latter. Therefore, it is assumed that the former is the primary pacemaker and the latter the secondary. As suggested by Hagiwara (1961), Type A neurons may spontaneously produce a prolonged depolarization which initiates a high-frequency train of impulses. It induces repetitive small synaptic potentials in other cells, increasing the excitability of the postsynaptic membrane and causing corresponding electrical activities.

The large cell behaves as a pacemaker, initiating the slow potential with superimposed spikes, when the activities of presynaptic nerve cells stop or are delayed (Figs. 6 and 7). Thus, the large cells may be considered the tertiary pacemaker. WATANABE and Bullock (1960) have demonstrated an electrical interaction between the follower and pacemaker cells; it consists of a positive feedback of the slow potential, which accelerates the activity of the pacemaker cell. The positive feedback of the slow potential change was clearly shown in the present experiment (Fig. 5). It is present between large cells and Type B cells. Such feedback, however, does not seem to be present between large cells and Type A cells, because the latter are not affected by the slow potential in the large cells.

As described by MAYNARD (1955), all cells in the cardiac ganglion are capable of initiating impulses without any synaptic inputs. During normal synaptic interactions, the ganglion produces periodic, coordinated electrical activities. In this case it is thought that the Type A presynaptic nerve cells play an important role as a pacemaker in initiating synchronous, periodic burst discharges of the ganglion.

\section{REFERENCES}

Alexandrowicz, J. S. (1932) The innervation of the heart of the crustacea. I. Decapoda. Quart. J. Micro. Sci., 75: 181-249.

Bullock, T. H. and Horridge, G. A. (1965) Structure and Function in the Nervous Systems of Invertebrates. W. H. Freeman, San Francisco, 223-225.

Bullock, T. H. and Terzuolo, C. A. (1957) Diverse forms of activity in the somata of spontaneous and integrating ganglion cells. J. Physiol., 138: 341-364.

Hagiwara, S. (1961) Nervous activities of the heart in crustacea. Ergebn. Biol., 24: 287311.

Hagiwara, S. and Bullock, T. H. (1957) Intracellular potentials in pacemaker and integrative neurons of the lobster cardiac ganglion. J. Cell. Comp. Physiol., 50: 25-47.

Hagiwara, S., Watanabe, A. and Satto, N. (1959) Potential changes in syncytial neurons of lobster cardiac ganglion. J. Neurophysiol., 22: 554-572.

Hoyle, G. and Wiersma, C. A. G. (1958) Excitation at neuromuscular junctions in crustacea. J. Physiol., 143: 403-425.

Hutter, O.F. and Trautwein, W. (1956) Vagal and sympathetic effects on the pacemaker fibers in the sinus venosus of the heart. J. Gen. Physiol., 39: 715-733.

Matsui, K. (1955) Spontaneous discharges of the isolated ganglionic trunk of the lobster heart (Panulirus japonicus). Sci. Rep. Tokyo Kyoiku Daigaku, B 7: 257-268.

MAYNARD, D. M. (1953) Activity in a crustacean ganglion. I. Cardio-inhibition and acceleration in Panulirus argus. Biol. Bull., 104: 156-170. 
MAYNARD, D. M. (1955) Activity in a crustacean ganglion. II. Pattern and interaction in burst formation. Biol. Bull., 109: 420-436.

OtANI, T. and Bullock, T.H. (1959) Effects of presetting the membrane potential of the soma of spontaneous and integrative ganglion cells. Physiol. Zool., 32: 104-114.

Shimahara, T. (1969a) The effect of the acceleratory nerve on the electrical activity of the lobster cardiac ganglion. Zool. Mag., 78: 351-355 (in Japanese).

ShImAHARA, T. (1969b) The inhibitory postsynaptic potential in the cardiac ganglion cell of the lobster, Panulirus japonicus. Sci. Rep. Tokyo Kyoiku Daigaku, B 14: 9-26.

Terzuolo, C. A. and Bullock, T. H. (1958) Acceleration and inhibition in crustacean ganglion cells. Arch. Ital. Biol., 96: 117-134.

Watanabe, A. (1958) The interaction of electrical activity among neurons of lobster cardiac ganglion. Jap. J. Physiol., 8: 305-318.

Watanabe, A. and Bullock, T. H. (1960) Modulation of activity of one neuron by subthreshold slow potentials in another in lobster cardiac ganglion. J. Gen. Physiol., 43: 1031-1045.

Watanabe, A., Obara, S. and AkiYama, T. (1968) Inhibitory synapses on pacemaker neurons in the heart ganglion of a stomatopod, Squilla oratoria. J. Gen. Physiol., 52: 908-924.

WAtanabe, A., Obara, S. and AkiYama, T. (1969) Acceleratory synapses on pacemaker neurons in the heart ganglion of a stomatopod, Squilla oratoria. J. Gen. Physiol., 54: 212-231.

Weidmann, S. (1956) Electrophysiologie der Herzmuskelfaser. Huber, Bern, Stuttgart.

Welsh, J. H. and MaYnard, D. M. (1951) Electrical activity of a simple ganglion. Fed. Proc., 10: 145.

Wiersma, C. A. G. and Bobbert, A. C. (1961) Membrane potential changes on activation in crustacean muscle fibres. Acta Physiol. Pharmacol. Neerl., 10: 51-72.

Wright, E. B. and Adelman, W. J. (1954) Accommodation in three single motor axons of the crayfish claw. J. Cell. Comp. Physiol., 43: 119-132. 